\title{
Au@Pt Nanoparticles Embedded in N-doped Graphene as sensor for Determination of Catechin
}

\author{
Shaoping Feng ${ }^{1,2,3}$, Shaoqin Hu ${ }^{1,2}$, Xianlan Chen ${ }^{1,2, *}$, Guowei Zhang ${ }^{1,2, *}$, Guiyang Liu ${ }^{1,2, *}$, Wei Liu ${ }^{1,2}$ \\ ${ }^{1}$ College of Science, Honghe University, Mengzi, 661199, Yunnan, P.R.China \\ ${ }^{2}$ Local Characteristic Resource Utilization and New Materials Key Laboratory of Universities in \\ Yunnan, Honghe University, Mengzi, 661199, Yunnan, China \\ ${ }^{3}$ School of Metallurgical and Ecological Engineering, University of Science and Technology Beijing, \\ Beijing 100083, China \\ *E-mail: 13489086418@163.com, shaopingfeng@126.com, 47225018@qq.com, alios@ 126.com
}

doi: $10.20964 / 2020.07 .25$

Received: 21 February 2020 / Accepted: 24 April 2020 / Published: 10 June 2020

In this study, $\mathrm{N}$-doped grapheme (NG) was synthesized by a hydrothermal method with graphemes oxide (GO) as raw material, melamine $\left(\mathrm{C}_{3} \mathrm{H}_{6} \mathrm{~N}_{6}\right)$ as reductant and nitrogen source. Results indicated that the nitrogen atoms have been effectively embedded into graphene when the composition mass ratio of GO: $\mathrm{C}_{3} \mathrm{H}_{6} \mathrm{~N}_{6}$ was 3:1. After that, the NG was saturated with Au@ Pt core-shell nanoparticles (Au@Pt NPs), which prepared by seed-mediated growth method, to obtain N-doped Au@Pt core-shell nanoparticles (NG-Au@Pt NPs). Then, the NG-Au@Pt NPs was dropped on Au electrode to construct an electrochemical sensor (NG-Au@Pt NPs/Au electrode) for sensing catechin. The electrochemical behaviors on modified electrode of catechin were investigated in detail at desired different conditions. The electrochemical sensor for catechin determination showed an excellent response and exhibited a wide linear range of $1.0 \times 10^{-7}-4.5 \times 10^{-5} \mathrm{M}$ with the detection limit of $2.85 \times 10^{-9} \mathrm{M}$. The recovery range and the precision relative standard deviation were $99.94-101.5 \%$ and $0.06-1.5 \%$ for determination of catechin in teas, respectively, indicating that the proposed method was expeditious and reasonable for catechin determination.

Keywords: N-doped graphene; Au@AuPt NPs; Catechin; Electrochemical sensor

\section{$\underline{\text { FULL TEXT }}$}

(C) 2020 The Authors. Published by ESG (www.electrochemsci.org). This article is an open access article distributed under the terms and conditions of the Creative Commons Attribution license (http://creativecommons.org/licenses/by/4.0/). 